\title{
Tritium in saliva measurements used for monitoring of exposed workers
}

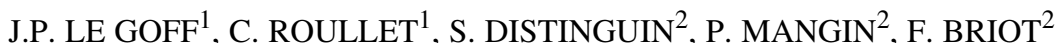

(Manuscript received 25 April 2006, accepted 8 October 2006)

\begin{abstract}
Simultaneous measurement of tritium in urine and saliva in exposed workers reveals differences in the kinetic fate of this radioelement in these two bodily fluids. During two years, four cases of accidental exposure, affecting seven workers, were used for these bioassays. Since the concentration of tritium increases much faster in saliva than in urine, a ratio estimated at 1 to 30 at about 30 minutes after contamination occurs, it is possible to consider saliva assay as an alternative to urine assay, which is more common practice today.
\end{abstract}

Keywords: tritium / tritiated water / saliva / internal contamination / bioassay

RÉSUMÉ Utilisation des mesures du tritium salvaire dans la surveillance des travailleurs exposés.

Les dosages simultanés de tritium dans les urines et la salive de travailleurs exposés à cette nuisance permettent de vérifier les cinétiques différentes de l'évolution du radioélément dans ces deux liquides biologiques. Sur une période de deux ans, quatre expositions incidentelles impliquant sept agents ont été exploitées afin d'effectuer ces dosages. L'augmentation de la concentration en tritium dans la salive, beaucoup plus précoce que dans l'urine, et que l'on peut estimer dans un rapport de 1 à 30 environ 30 minutes après la contamination, permet d'envisager le dosage salivaire comme l'alternative au dosage urinaire, aujourd'hui le plus couramment pratiqué.

\section{Introduction}

Tritium is a hydrogen isotope with a half-life of 12.34 years; it replaces the hydrogen atoms in the form of a gas, tritiated water (HTO) or in organic molecules (OBT). It enters the body by inhalation, ingestion, transcutaneous diffusion or through a wound. The main form for transfer to the blood is HTO; only a small portion of inhaled tritium gas is converted to HTO. The intake of HTO by any pathway is fast and efficient: about $99 \%$ is absorbed in a few minutes. The spread of HTO in extra- and intra-cellular fluids is rapid, and it is evenly distributed. Aside from a small fraction which enters biological molecules, the kinetics of tritium is the same as for free water. ICRP Publication 56 (1989) gives a twocompartment model for HTO: one contains $97 \%$ of the radioactivity entering the blood and the other contains the remaining $3 \%$ converted to OBT.

${ }^{1}$ CEA, Service de Santé au Travail, Centre de Valduc/CEA/DAM, 21120 Is-sur-Tille, France.

${ }^{2}$ CEA, Laboratoire d'Analyses de Biologie Médicale, Centre de Valduc/CEA/DAM, 21120 Is-sur-Tille, France. 
In experiments, when HTO is injected intravenously to volunteers (Balanov et al., 1974), the level of HTO radioactivity in saliva attains that found in the peripheral blood after about 20 minutes, and these levels are at equilibrium with that found in urine after a variable period of time, which depends on the initial urine volume and urinary output.

In ICRP Publication 23 (1975), the 24-hour urinary output of reference man is $1400 \mathrm{ml}$ (1000 $\mathrm{ml}$ for reference woman), and saliva production is 1 to 2 litres per 24-hour period.

Coppen and Gibbons (1960) report equilibrium activity in saliva and urine three hours after oral absorption of HTO by 6 healthy adults.

A study on 34 adults (Hesp et al., 1982) indicates a non-significant difference in activity levels in saliva and plasma 3.5 hours after HTO ingestion.

Monitoring of personnel in plants where tritium is used is generally done by measuring tritium activity in urine. When exposure is suspected it is important to obtain results rapidly, in order to avoid detaining possibly contaminated operatives at their workplace for too long and, if necessary, to be able to initiate appropriate treatment. Bioassays on saliva would appear to meet this requirement.

\section{Equipment and methods}

\subsection{Description of accidental exposure incidents}

The study focussed on four of the exposure incidents. The first three were cases of contamination by inhalation, each involving two workers (for safety reasons these workstations are manned by two workers at a time). One operative was involved in two of these incidents. The fourth was a case of contamination through a finger wound in a tritium-contaminated environment. This study took place during two years because, fortunately, these incidents occur exceptionally during the industrial process.

\subsection{Assays performed}

Urine and saliva assays were conducted on the seven workers involved. The first samples were taken as soon as possible after the incident was reported (the exact time between incident and sample-taking is sometimes difficult to ascertain). Further samples were then taken at regular intervals, depending on the workers' availability, over a period of about two hours. 


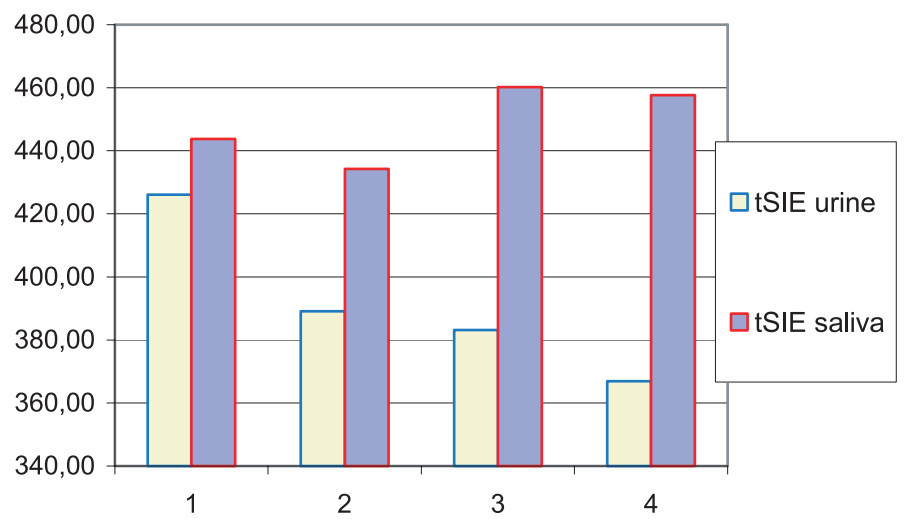

Figure 1 - Quenching factor in urine and saliva.

Facteur d'atténuation dans les urines et les salives.

\subsection{Sampling methods}

Urine samples are taken without any special precautions and without a preservative, in a $50 \mathrm{ml}$ plastic bottle. Saliva is obtained by having the subject chew a cylindrical cotton swab, $3.8 \mathrm{~cm}$ long and $1 \mathrm{~cm}$ in diameter, which is then placed in a plastic tube for centrifuging and recovery of the liquid saliva from the cotton $\left(\right.$ SALIVETTE $^{\circledR}$, SARSTEDT $^{\circledR}$ ).

\subsection{Tritium assay}

This test is done by mixing the biological sample with a scintillation cocktail (INSTAGEL ${ }^{\circledR}$ ) in a ratio of 1 to 10 and performing a count with a PACKARD 2700TR liquid scintillation analyser. The quenching rate is determined by reference to the index number of the constructor t-SIE (a transform of the spectral index of the sample), whose value is inversely proportional to the quenching rate. In four of the workers who underwent the assay, we determined the value of t-SIE in saliva and urine (Fig. 1); the t-SIE in saliva is invariably higher than in urine, which indicates a lower quenching rate due to the lower pigment and colorant content of saliva.

\subsection{Equilibrium counts}

From 17 workers, not those involved in our exposure study but also exposed to tritium, we took saliva and urine samples more than two hours after their exposure. The results presented in Figure 2, confirm that the tritium concentration is the 


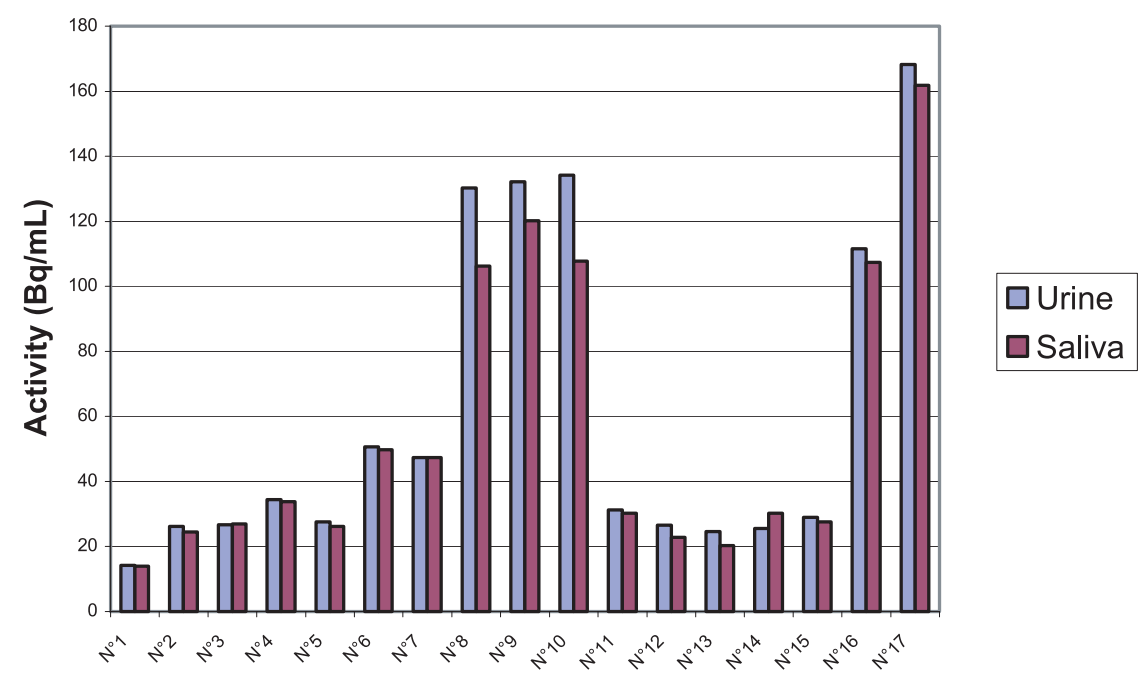

Figure 2 - Tritium concentration in urine and saliva from 17 workers more than 2 hours after exposure. Concentration en tritium dans les urines et la salives de 17 agents, plus de 2 heures après une exposition.

same in saliva and urine. For these workers and for those who are involved in the incidents described further the radioactive intake remains strongly below the prescribed limits.

\section{Results and discussion concerning counts following exposure incidents}

It is not possible to determine precisely the time of contamination. A significative increase in tritium activity in a building will trigger the alert procedure, but the time between the start of worker contamination and the alert is variable and unknown. For the response team and the radiation protection department the first priority is to get people to safety and confine the contamination. Biological sample-taking legitimately takes second place. Experience shows that the average time between an alert and the first sample is fifteen to twenty minutes.

\subsection{Incident No. 1 (workers $A$ and B)}

On the basis of fifteen minutes elapsed time between the first urine samples and the saliva samples, the tritium concentration in saliva is 20 to 40 times greater than in urine. In our experience it is necessary to wait about two hours after tritium contamination to observe the maximum radioactivity in urine. Since we were not 


\section{Table I}

Results of tritium in saliva and urine for the workers involved in incidents 1, 2, 3 and 4. Résultats en tritium salivaire et urinaire des travailleurs impliqués dans les incidents 1, 2, 3 et 4.

\begin{tabular}{|c|c|c|c|}
\hline Incident / Subject & $\Delta$ Time & Activity in urine $\mathrm{Bq} \mathrm{ml} l^{-1}$ & Activity in saliva $\mathrm{Bq} \mathrm{ml^{-1 }}$ \\
\hline \multirow{5}{*}{ No. $1 /$ A } & 00:00 & 7.8 & - \\
\hline & $00: 15$ & 22.1 (extrapolation) & 886.7 \\
\hline & $00: 45$ & 50.7 (extrapolation) & 338.3 \\
\hline & $01: 15$ & 79.3 (extrapolation) & 186.9 \\
\hline & $01: 45$ & 107.9 & 106.4 \\
\hline \multirow{5}{*}{ No. 1 / B } & 0:00 & 27.7 & - \\
\hline & $0: 15$ & 37.4 (extrapolation) & 748.12 \\
\hline & $0: 45$ & 56.8 (extrapolation) & 208.5 \\
\hline & $1: 15$ & 76.3 (extrapolation) & 136.7 \\
\hline & $1: 45$ & 95.7 & 104 \\
\hline \multirow{2}{*}{ No. 2 / C } & 00:00 & 93.2 & 194.3 \\
\hline & $00: 40$ & 166.4 & 176 \\
\hline \multirow{2}{*}{ No. 2 / D } & $0: 00$ & 58.7 & 101.5 \\
\hline & $0: 40$ & 75.5 & 72 \\
\hline \multirow{3}{*}{ No. 3 / E } & 00:00 & 17.3 & 173.1 \\
\hline & 02:00 & 34.8 & 36.63 \\
\hline & 04:00 & 40.7 & 39.43 \\
\hline \multirow{3}{*}{ No. 3 / F } & 0:00 & 8.4 & 75.8 \\
\hline & 2:00 & 21.34 & 26.47 \\
\hline & $4: 00$ & 27.1 & 24.3 \\
\hline \multirow{4}{*}{ No. 4 / G } & $00: 30$ & 1.10 & 24.67 \\
\hline & $01: 15$ & 1.41 & 11.20 \\
\hline & $01: 35$ & 1.84 & 6.50 \\
\hline & 02:05 & 1.50 & 3.80 \\
\hline
\end{tabular}

able to take urine samples at $15^{\prime}, 45^{\prime}$ and 1 hour 15', we assumed linear growth in the tritium concentration between time 0 and 1 hour 45', which is in line with the existing bibliographical data. Table I shows the evolution of saliva versus urine with time.

\subsection{Incident No. 2 (workers $C$ and D)}

Tritium concentrations in saliva are 1.7 to 2 times greater than in urine. The smaller difference between saliva and urine (Tab. I), compared to incident No.1, 
may be due to the following factors:

- in this case the time between contamination and the first samples was probably greater than 30 minutes;

- or, the contamination may have been gradual;

- or, decay gradients for saliva activity may be steeper.

\subsection{Incident No. 3 (workers $E$ and $F$ )}

Tritium concentrations in saliva are 9 to 10 times greater than in urine (Tab. I). Equilibrium was reached within two hours after the first samples were taken.

\subsection{Incident No. 4 (worker G)}

In this case (a cut on the thumb) the time of contamination and the time to first sample are known. The ratio of 1 to 25 between tritium in urine and tritium in saliva at about 30 minutes after contamination (Tab. I) is probably close to reality, provided there had been no previous contamination by inhalation or transcutaneously.

\section{Conclusions}

The results from these four cases of exposure to tritium are fairly close to those in the literature, as regards the kinetics of tritium in the various compartments of the body.

In view of the advantage of having an early result from assaying tritium in saliva, we would recommend using the SALIVETTE ${ }^{\circledR}$.

\subsection{For routine monitoring}

Female staff may be reluctant to supply urine samples during their menstrual periods. Saliva sampling provides an alternative.

Some workers have difficulty in urinating upon request.

For visitors leaving our facilities using tritium, unlike other nuclear facilities, there is no "hand and foot" type counter for monitoring contamination. Although the regular urine checks for staff accompanying visitors ensure that there is no contamination during the visit (except where contact contamination could occur), saliva sampling for visitors leaving a facility would provide additional assurance.

\subsection{Monitoring after an incident}

The current procedure is to take a first urine sample and repeat it two hours later. This is a cause of stress during the waiting period, and it also means that if the 
incident occurs at the end of the working day, workers must be delayed before returning home. Here again, some staff members involved may have trouble urinating (waiting for the result of a biological sample after possible radiological contamination can be a stressful experience), and if such subjects drink large quantities of water in order to urinate they could suffer water intoxication. Gardner and Gutmann (2002) have described water intoxication in a subject undergoing a urine screening test for addictive substances; they mention a number of publications which warn that stress, intense physical activity and other factors may prevent the kidneys from rapidly excreting a large quantity of liquid.

If the same level of tritium activity is found in saliva and urine, in a check after an incident, it can be assumed that equilibrium has been reached, without having to wait out the two-hour period. The result of an initial saliva sample, before it reaches equilibrium with urine, can be used to estimate the maximum level of contamination.

When a large number of people have to be checked, saliva sampling would be easier to organise than urine samples, which require an adequate number of toilets and sometimes cause embarrassment to female subjects. Naturally, this research should be followed up by studies on other cases of contamination to validate our data, which is too narrow.

\section{REFERENCES}

Balanov M.I., Dolgirev E.I., Likhtarev I.A. (1974) Exchange kinetics and dosimerty of tritium oxyde in man for different routes of administration, Health Phys. 27, 367-375.

Coppen A.J., Gibbons J.L. (1960) Salive-Serum Ratios of Tritium after the Administration of Tritiated Water, Nature 186, 724-725.

Gardner J.W., Gutmann F.D. (2002) Fatal Water Intoxication of an Army Trainee during Urine Drug Testing, Milit. Med. 167, 435-437.

Hesp R., Smith T., Veall N. (1982) The use of saliva samples to determine total body water by tritium dilution, Clin. Phys. Physiol. Meas. 3, 155-157.

ICRP Publication 23 (1975) Reference Man: Anatomical, Physical and Metabolic Characteristics. Pergamon Press, Oxford.

ICRP Publication 56 (1989) Age-dependent Doses to Members of the Public from Intake of Radionuclides: Part 1, Ann. ICRP 20(2) 